\title{
Feasibility Limits for a Hybrid System with Ocean Wave and Ocean Current Power Plants in Southern Coast of Brazil
}

\author{
Andrea Fischer ${ }^{1}$, Jones S. Silva ${ }^{2}$, Alexandre Beluco² \\ ${ }^{1}$ Instituto Federal Sul Riograndense (IFSUL), Pelotas, Brazil \\ ${ }^{2}$ Universidade Federal do Rio Grande do Sul (UFRGS), Porto Alegre, Brazil \\ Email: albelcuo@iph.ufrgs.br
}

How to cite this paper: Fischer, A., Silva, J.S. and Beluco, A. (2021) Feasibility Limits for a Hybrid System with Ocean Wave and Ocean Current Power Plants in Southern Coast of Brazil. Computational Water, Energy, and Environmental Engineering, 10, 1-17.

https://doi.org/10.4236/cweee.2021.101001

Received: July 19, 2020

Accepted: November 28, 2020

Published: December 1, 2020

Copyright $\odot 2021$ by author(s) and Scientific Research Publishing Inc. This work is licensed under the Creative Commons Attribution International License (CC BY 4.0).

http://creativecommons.org/licenses/by/4.0/

(c) (i) Open Access

\begin{abstract}
Some types of renewable energy have been experiencing rapid evolution in recent decades, notably among the energies associated with the oceans, such as wave and current energies. The development of new energy conversion technologies for these two forms of energy has been offering a large number of equipment configurations and plant geometries for energy conversion. This process can be implemented aiming at the result of feasibility studies in places with energy potentials, establishing minimum feasibility limits to be reached. This work aims to contribute in this sense with a feasibility study of a system with ocean wave power plants and with socio-current power plants to be operated on the southern coast of Brazil. This study evaluates a hybrid system with contributions from energy supplies obtained from wave plants and current plants, connected to the grid and supplying the demand of the municipalities in the North Coast region of the State of Rio Grande do Sul, the southernmost state of Brazil. The study was carried out with simulations with the Homer Legacy software, with some adaptations for the simulation of ocean wave plants and ocean current plants. The results indicate that the ocean wave power plants were viable in the vast majority of simulated scenarios, while the ocean current power plants were viable in the scenarios with more intense average ocean current speeds and with more expensive energy acquired from the interconnected system.
\end{abstract}

\section{Keywords}

Hybrid Energy Systems, Ocean Wave Power Plants, Ocean Current Power Plants, Feasibility Limits, New Technologies, Software Homer 


\section{Introduction}

Among the different alternatives for obtaining energy supplies from renewable resources, some have reached a stage of technical and economic maturity, while other alternatives experience different stages of development. Among the alternatives that can be considered mature are hydroelectric energy, wind energy and solar energy, in some of their most popular forms, such as their applications for heating water and photovoltaic modules, for the direct availability of electrical energy [1]. Among the alternatives under development, energies related to the oceans, such as wave energy, current and tidal energy, in addition to thermal ocean energy, as well as geothermal energy and some other forms, can be listed. less popular or less available energy [1].

Renewable resources have characteristics of intermittency and variability that make it very difficult to use them in interconnected systems of continental extensions, as is the case of the Brazilian energy system. Usually, their use requires joint operation with energy storage devices, in addition to appropriate government policies. Ocean waves and currents however have characteristics of relative predictability that differentiate them from other renewable resources. This better predictability can guarantee priority investments in the development of alternative energy sources [2].

Renewable resources usually provide energy supplies in concentrations more appropriate to distributed generation than to their incorporation into large interconnected systems. The complementarity between renewable resources [3] [4] can contribute decisively to this scenario. In addition, wave and ocean current energies will become energy alternatives when other alternatives are not available. Their locations usually away from urban centers and their relative predictability therefore contribute to a larger generation of energy, possibly appropriate for large systems.

There are many technologies available in other areas of ocean resource exploitation [5] [6] [7] [8] [9] that can be adapted for application in the field of energy generation from renewable resources [9] [10]. There are also many initiatives for the development of means and devices for converting energy from ocean waves and ocean currents, among other forms of energy available in the oceans [2] [11] [12]. Efforts focused on the means and devices that are closest to reaching technical and commercial maturities are necessary and the demand for energy supplies will guide this process.

In this scenario, an important tool for managers looking for alternatives to obtain energy supplies that are reliable and that prove to be viable is the establishment of feasibility spaces for investment in new energy alternatives. The concept recently presented [5] is related to the energy resource to be used and is also related to the technology (under development) to be applied, obviously depending on its stage of technical and economic maturity, and is also related to the local characteristics of the energy system in which the technological solution will be inserted.

In this way, the concept of "feasibility space" can be considered as an objective to be achieved. The feasibility space is then a set of minimum and maximum 
limit values for variables and parameters that influence the technical and economic feasibility of a project. The investment in the implementation of energy conversion devices or in the maturation process of a given technology can be guided by the feasibility values to be achieved, that is, the viability space.

This study aims to determine the feasibility space, according to the concept presented by Silva et al. in a scientific article [5] [13] and later proposed as a method [14], for obtaining energy supplies through ocean wave energy and ocean current energy conversion devices on the southern coast of Brazil, along the north coast of the State of Rio Grande do Sul. It is important to emphasize that further studies on the energy potentials in the region should be undertaken.

The article consists of four sections, in addition to this Introduction. The next section characterizes the region in which the ocean wave and ocean current plants would be operated and the next section presents the simulations performed with the Homer Legacy software [15] and the hybrid system under study. Subsequent sections discuss the results and present the final conclusions.

\section{The Area under Study}

This study was carried out with the goal of establishing lower viability limits for the implementation of ocean wave plants and ocean currents to supply energy to the region that is known as the North Coast of the State of Rio Grande do Sul (which can be located on Google Maps at https://goo.gl/maps/5Ds8PddHEMGsGnw59), which is the southernmost state in Brazil. Figure 1 shows a portion of the State's coastline (https://goo.gl/maps/4Ekb8f7yhQ9kaRRQ8), approximately between the city of Rio Grande (https://goo.gl/maps/bh883zGXmZkLt1tN9) and the city of Torres (https://goo.gl/maps/dYwwXoxQRMA1CmedA). This portion includes more to the north the municipalities whose demand must be met, and also includes in the center and further south the region most appropriate for ocean wave conversion devices and the continental shelf, most appropriate for installing energy conversion devices from ocean currents.

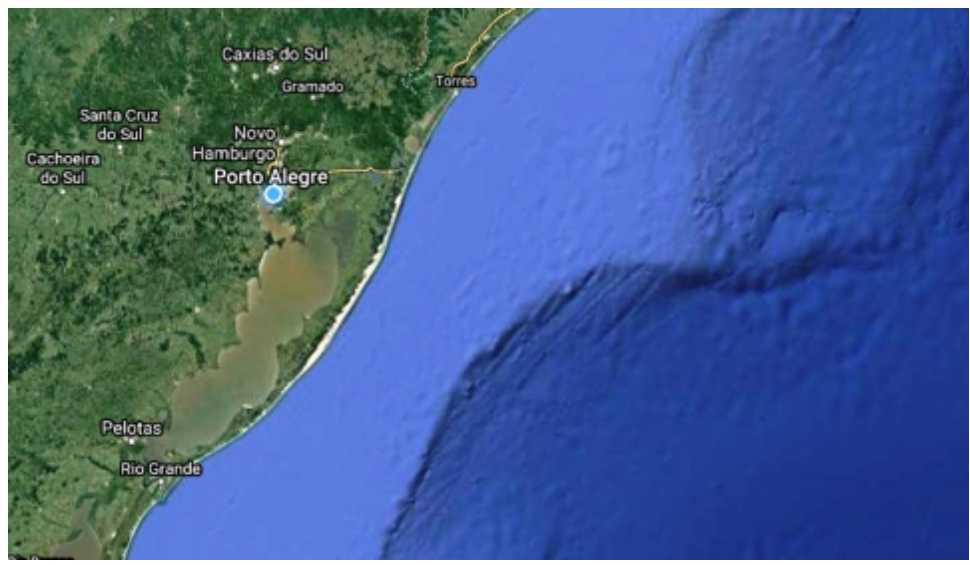

Figure 1. Coastal region of the State of Rio Grande do Sul, including the region considered in this study. 
The municipalities in the region called the North Coast of Rio Grande do Sul appear in Figure 1 of Ref. [10]. The region is formed by 25 municipalities, totaling 365,026 inhabitants, according to the 2010 census [16], with Torres, Capão da Canoa, Tramandaí, Osório and Santo Antônio da Patrulha being the largest municipalities, each with approximately 40,000 inhabitants. The population in this region is almost tenfold during the summer months, between December and March.

Figure 2 of Ref. [10] shows the approximate location of ocean wave plants on the coast of the State, in an excerpt from the previous figure, Figure 1, from the same reference. The potential for power generation from waves in the region [11]-[17] is $8.6 \mathrm{~kW}$ per meter of wavefront, average annual value, varying between $14.0 \mathrm{~kW}$ per meter of wavefront for May and $4.0 \mathrm{~kW}$ per meter of wavefront for January, which can be considered medium intensity when compared to potentials in other regions of the world. The article by Silva et al. [10] establishes minimum limits for the feasibility of investments for obtaining energy supplies from ocean waves in the region.

Figure 1 above shows the extensive continental shelf area (in light blue) available in this stretch of the Brazilian coast, suitable for the conversion of energy from ocean currents. In this region, the continental shelf has a width of up to $200 \mathrm{~km}$ and average depths of 20 to 30 meters. The work of Fischer et al. [18] [19] presents an initial characterization of ocean currents in the region, based on a relatively limited set of measurements (which points to the need for new exploration campaigns to be undertaken on the southern coast of Brazil). Unfortunately, the energy potential found so far is insufficient for power generation from ocean currents.

\section{Homer Software and the Hybrid System under Study}

Homer software [20] [21] is a well-known software for simulating micro and small scale power generation systems, proving to be very suitable [22] over the years for simulating hybrid systems. Homer simulates one year of operation of

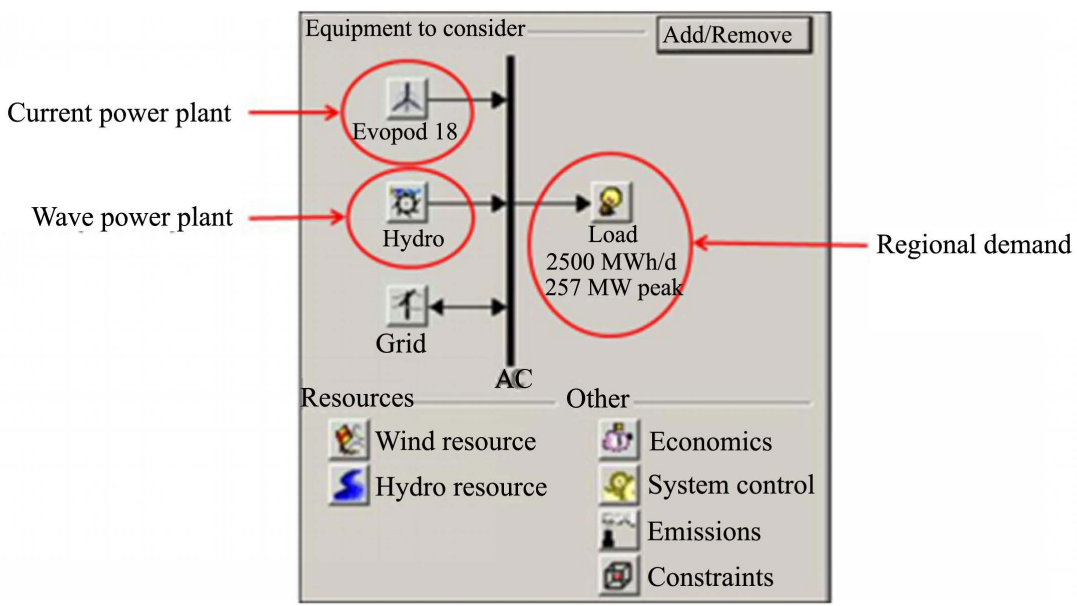

Figure 2. Schematic diagram of the hybrid system under study. 
the system under study and performs an economic assessment for the useful life considered for the project. Homer selects the values of the appropriate optimization variables for the ideal solutions, those that reduce the total value of the net present cost, considering the period of analysis of the project. In addition, Homer also allows a sensitivity analysis of some variables selected for the study.

Considering this study, the simulations were performed with the Legacy version of Homer for a 20 -year operating period, with annual interest of $12 \%$ and an internal rate of return of $6 \%$. The US dollar was adopted as a reference for all component costs, due to the good availability of information, in addition to allowing an assessment that is less subject to issues related to instabilities typical of the economic and financial reality of Brazil. Figure 2 shows a schematic diagram of the proposed hybrid system, considered in this study to assess the feasibility limits for the implementation and operation of ocean wave power plants and ocean current power plants on the southern coast of Brazil.

Homer software, in its version Legacy (version 2.68 beta), contains internal models for simulating hydroelectric plants, wind turbines and PV modules, among devices for energy conversion, in addition to systems based on fossil fuels. Ref. [23] presents very complete instructions on how to obtain this version of Homer and presents the availability of several files with case studies. Among these files made available [24], some deal with the improvised use of Homer's internal models to simulate components not foreseen in its original design. This is the case of the study undertaken in this article, which considers the simulation of ocean wave plants and ocean current plants, whose models are not part of Homer. Models can also be built with storage capacity [25] [26].

Figure 2 shows the ocean current plant being simulated with the model for wind turbines, as described by Fischer et al. [27] and also shows the ocean wave plant being simulated with the hydroelectric plant model, as presented by Silva et al. [28]. This figure also shows that the system under study is connected to an energy system and that it meets a demand called regional. This figure is an excerpt from the Homer software control panel and shows the friendly input of information to prescribe the simulations to be performed. This figure also shows, at the bottom left, the entry of energy availability data.

Figure 3 shows an hourly series of ocean current velocity data obtained for the region of Tramandaí, on the coast of the State of Rio Grande do Sul, the southernmost state in Brazil, obtained as described by Ref. [18]. This data series is adapted to be inserted in Homer so that the model of wind turbines can be used for the simulation of equipment for energy conversion from ocean currents. Ref. [27] describes the adaptation of these data for use with Homer software. The current speeds in southern Brazil are relatively small, but the study was also carried out with higher speeds in a sensitivity analysis aiming to establish the limits of feasibility.

Figure 4 shows an hourly series of flows that was built according to instructions from Ref. [28] as a combination of significant heights and periods of energy, so that energy availability data for waves on the coast of Rio Grande do Sul 


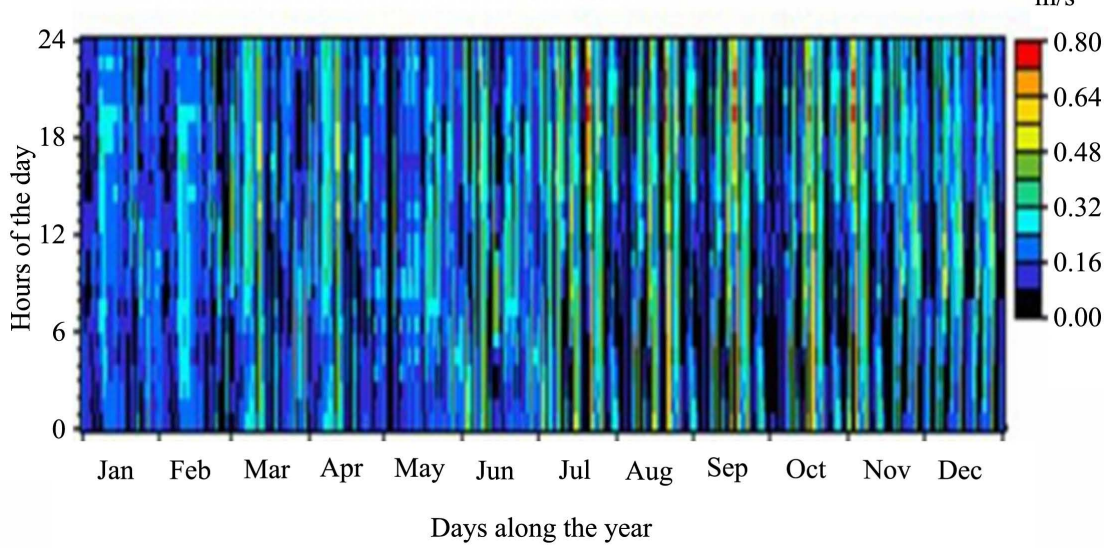

Figure 3. Hourly series of ocean current speeds for the region of the hybrid system under study, adapted for use with Homer.

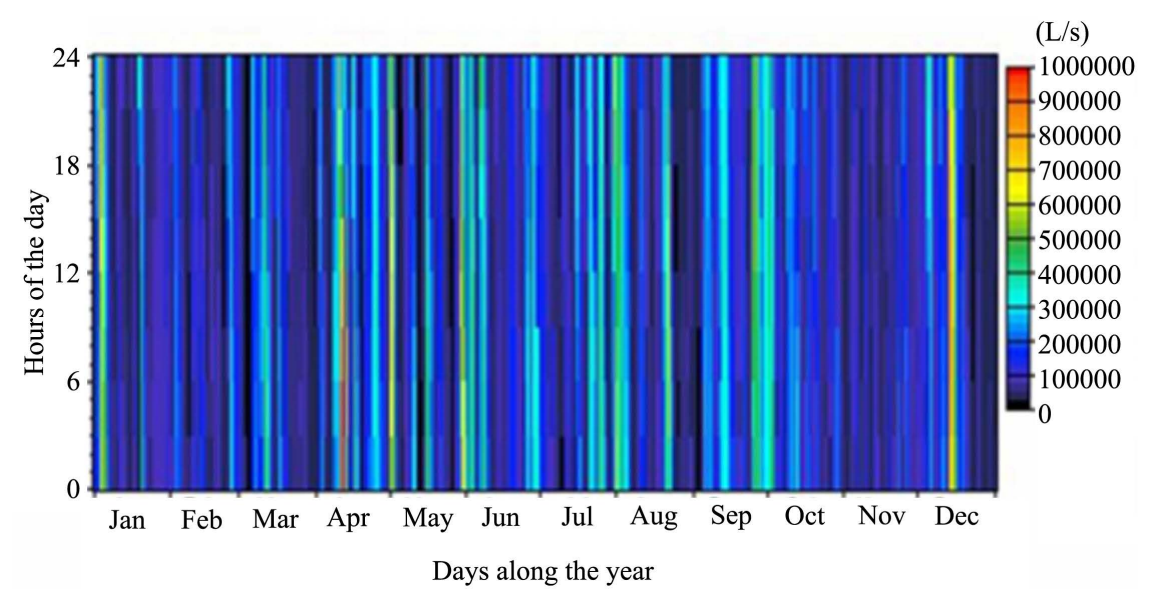

Figure 4. Hourly series of stream flows equivalent to the combination of significant height and period of energy of ocean waves for the region of the hybrid system under study, adapted for use with Homer.

can be inserted in Homer and so that the hydroelectric plant model can be used for the simulation of equipment for energy conversion from ocean waves. Ref. [17] describes how energy availability data was obtained also in Tramandaí, on the coast of the State of Rio Grande do Sul. Ref. [10] used these data to propose the method considered in this study, for establishing a viability space for new technologies.

Figure 5 shows the hourly demand for electricity for the study region, corresponding to the year 2011. It is possible to observe how the demand for electricity is much higher during the summer months, between December and March, mainly between the late afternoon and early morning. There is also a much lower demand during the night in the months outside this summer period. The average annual demand is $105 \mathrm{MW}$, with a peak demand of $259 \mathrm{MW}$ and an average daily consumption of approximately $2500 \mathrm{MWh}$. The average demand in the summer is $144 \mathrm{MW}$, while in the winter months it is $88 \mathrm{MW}$. Even with a strong increase in the population during the summer months, the average power 


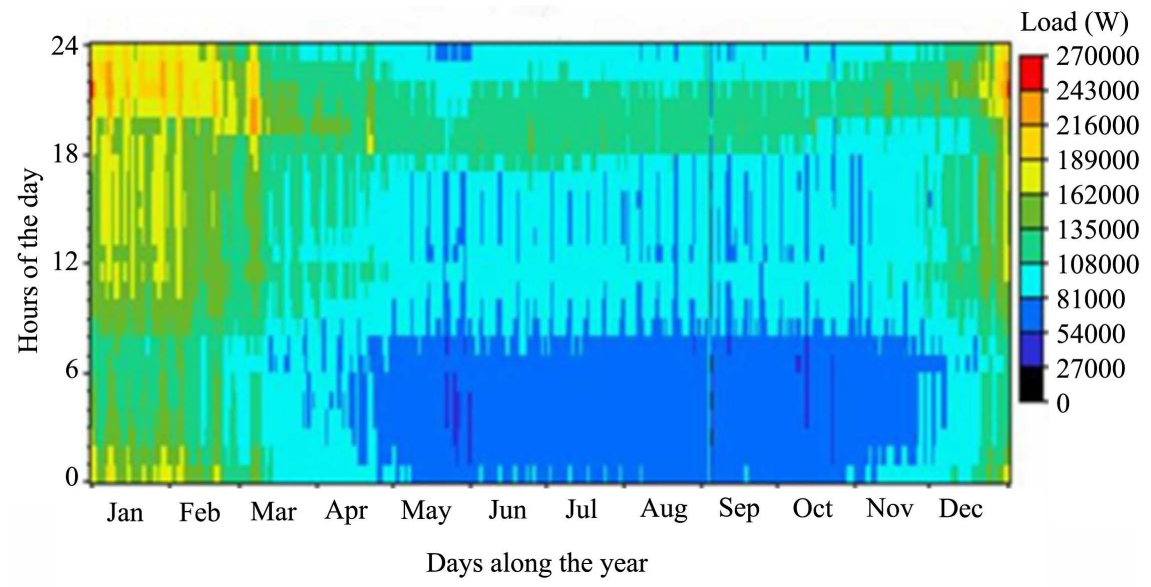

Figure 5. Hourly series of electrical demand from consumers in the region of the hybrid system under study, for the year 2011.

consumed does not grow proportionally, mainly due to the custom of traveling to the coast, mainly during the weekends.

The simulations were performed with the following values for the following optimization variables: 0,20 and 45 equipment or turbines for converting energy from ocean currents (appearing in Homer as wind turbines). The simulations were carried out with the following values for the sensitivity variables: 0.5, 1.0 and 2.0 for the multiplicative factor of capital cost, replacement cost and maintenance and operation cost of the equipment for energy conversion. ocean currents; $0.162 \mathrm{~m} / \mathrm{s}, 1000 \mathrm{~m} / \mathrm{s}$ and $2000 \mathrm{~m} / \mathrm{s}$ for the average velocity of ocean currents in the region of the system under study (appearing in Homer as average wind speed); US\$ 0.095 per kWh, US\$ 0.162 per kWh and US\$ 0.223 per kWh for the cost of electricity purchased from the interconnected system; US\$ $400,000,000$, US $\$ 555,000,000$ and US $\$ 1,100,000,000$ for the capital cost of the ocean wave power plant (appearing in Homer as a hydroelectric power plant).

The file with results of the simulations is available in Ref. [29].

\section{Results and Discussion}

This section presents eleven figures with optimization spaces provided by Homer. The results are discussed throughout the presentation of the figures. The first six of these eleven figures show optimization spaces with multiplicative factor of the ocean current power plant's capital cost as a function of current speeds, while the other five figures show the multiplicative factor of the ocean currents plant's capital cost as a function of capital cost of the ocean wave power plant.

Figure 6 shows the optimization space provided by Homer for the simulation of the hybrid system shown in Figure 2 for the multiplication factor of the cost of acquisition or implantation of the ocean currents plant as a function of the average speed of the ocean currents, for an ocean wave plant with a capital cost of US\$555,000,000 and for electricity purchased from the interconnected system 


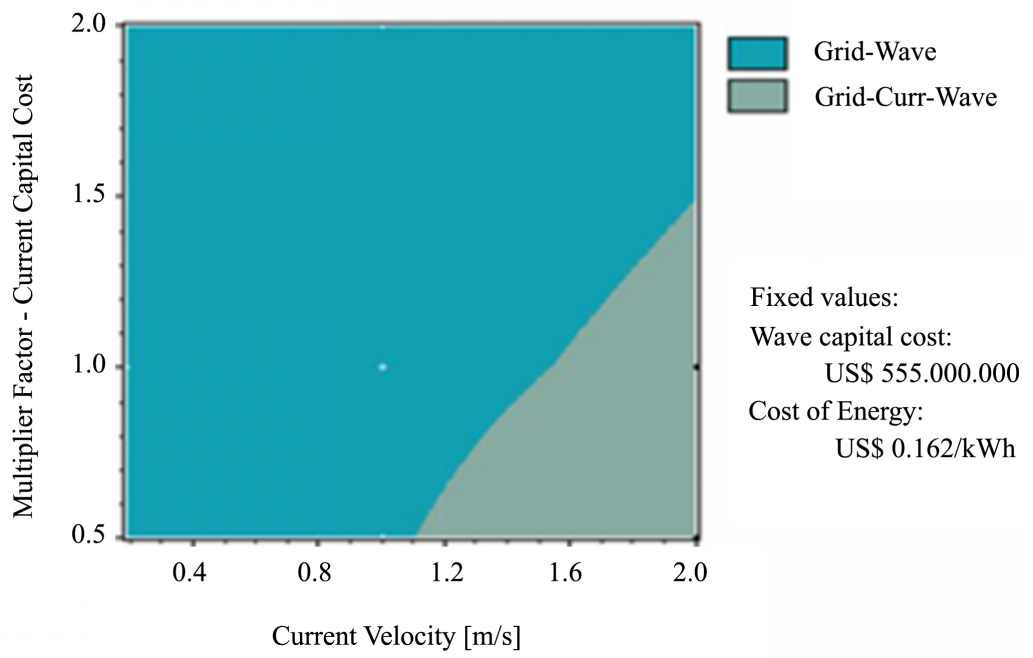

Figure 6. Optimization space for the multiplicative factor of the capital cost of the ocean current power plant (in US\$ millions) as a function of the average speed of ocean currents (in $\mathrm{m} / \mathrm{s}$ ), with the capital cost of the ocean wave power plant equal to US $\$ 555,000,000$ and electricity purchased from the energy system at US\$ 0.162 per kWh.

at US\$ 0.162 per $\mathrm{kWh}$. The reference value for this multiplicative factor is equal to US\$12,210,000.

This figure shows that the ocean wave power plant is feasible in all simulated situations, while the ocean current power plant is only feasible with ocean current speeds above $1.1 \mathrm{~m} / \mathrm{s}$ and for a capital cost equal to half the initial reference value. For $1.6 \mathrm{~m} / \mathrm{s}$, the hybrid system is feasible with the cost initially adopted per turbine, while, for speeds close to $2 \mathrm{~m} / \mathrm{s}$, the capital cost of the ocean current power plant can be approximately 1.5 times higher and yet viable.

Figure 7 and Figure 8 show optimization spaces for a multiplicative factor of the capital cost of the ocean current power plant as a function of the average speed of ocean currents, for an ocean wave power plant with a capital cost of US $\$ 555,000,000$ and for electricity purchased from the interconnected system at US\$ 0.095 per kWh and US\$ 0.223 per kWh respectively.

In the first of these two, the wave power plant again showed feasibility across the scope of the optimization space, but the lower price of electricity obtained from the grid made the feasibility field for the current power plant smaller. As can be seen, for a speed of $1.2 \mathrm{~m} / \mathrm{s}$ the cost should be half the cost initially estimated for the power plant and for speeds close to $2 \mathrm{~m} / \mathrm{s}$ there is feasibility with the cost considered as a reference.

In Figure 8, the ocean wave power plant remains feasible over the entire extension of the optimization space, while the ocean current power plant is shown to be feasible at current speeds of $1.06 \mathrm{~m} / \mathrm{s}$. For higher current speeds, close to 2 $\mathrm{m} / \mathrm{s}$, the cost of the ocean current power plant after which it becomes feasible is around 1.7 times higher than the initially stipulated reference value.

Figure 9 and Figure 10 show the optimization spaces for the multiplicative factor of the capital cost of the ocean current power plant as a function of the 


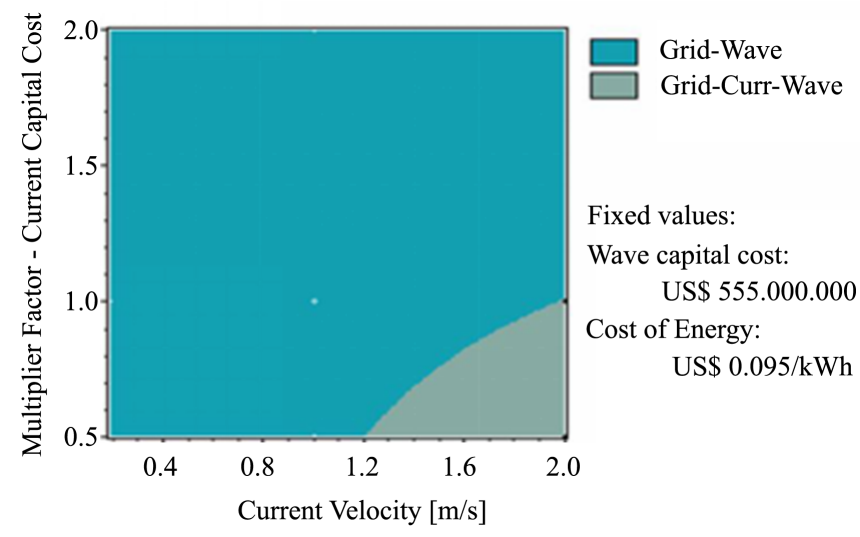

Figure 7. Optimization space for the multiplicative factor of the capital cost of the ocean current power plant (in US\$ millions) as a function of the average speed of ocean currents (in $\mathrm{m} / \mathrm{s}$ ), with the capital cost of the ocean wave power plant equal to US\$555,000,000 and electricity purchased from the energy system at US $\$ 0.095$ per kWh.

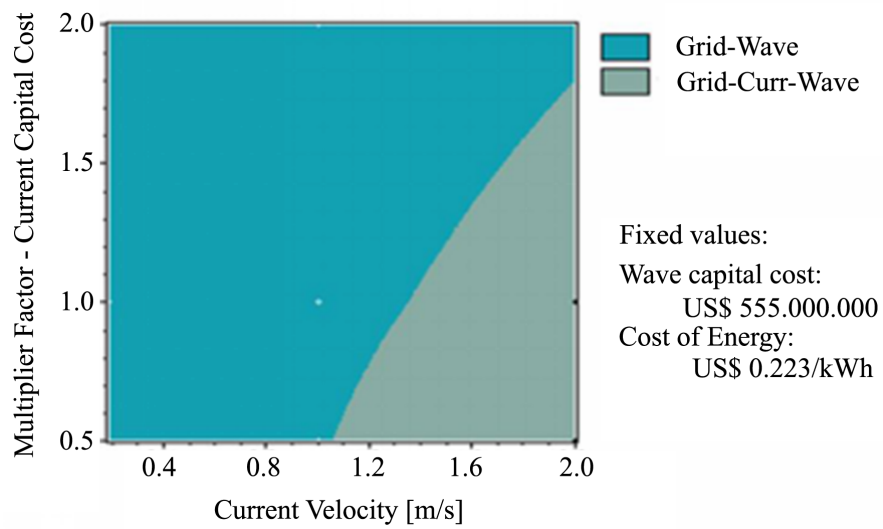

Figure 8. Optimization space for the multiplicative factor of the capital cost of the ocean current power plant (in US\$ millions) as a function of the average speed of ocean currents (in $\mathrm{m} / \mathrm{s}$ ), with the capital cost of the ocean wave power plant equal to US\$555,000,000 and electricity purchased from the energy system at US\$ 0.223 per kWh.

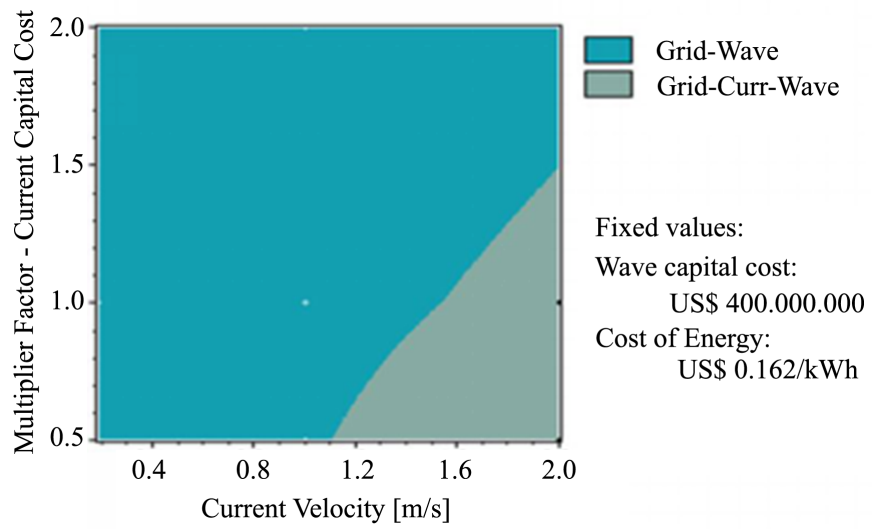

Figure 9. Optimization space for the multiplicative factor of the capital cost of the ocean current power plant (in US\$ millions) as a function of the average speed of ocean currents (in $\mathrm{m} / \mathrm{s}$ ), with the capital cost of the ocean wave power plant equal to US $\$ 400,000,000$ and electricity purchased from the energy system at US\$ 0.162 per $\mathrm{kWh}$. 


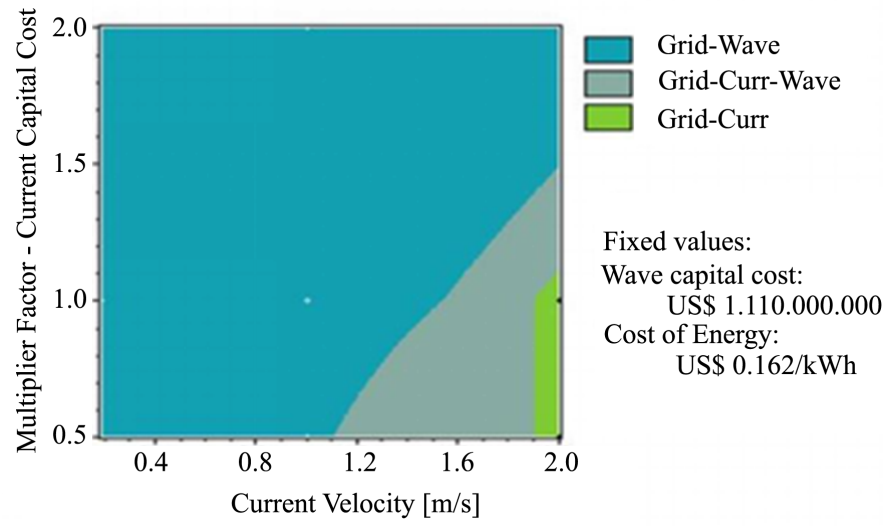

Figure 10. Optimization space for the multiplicative factor of the capital cost of the ocean current power plant (in US\$ millions) as a function of the average speed of ocean currents (in $\mathrm{m} / \mathrm{s}$ ), with the capital cost of the ocean wave power plant equal to US\$1,110,000,000 and electricity purchased from the energy system at US\$ 0.162 per kWh.

average speed of ocean currents, for electricity purchased from the interconnected system at US\$ 0.162 per $\mathrm{kWh}$ and for ocean wave power plant with capital costs respectively of US $\$ 400,000,000$ and. US $\$ 1,110,000,000$. The amount of US $\$ 400,000,000$ was obtained by Silva [30] in his master's work. As in the previous results, the ocean wave power plant is feasible throughout the optimization spaces.

In these two figures, the areas of the optimization spaces that include optimal solutions with ocean current power plants are practically identical, but the second figure of these two presents a narrow band in its lower right part with solutions that do not include ocean wave power plants. The increase in the capital cost of the ocean wave power plant, combined with the higher speeds of ocean currents considered in the simulations, led to hybrid solutions including current plants and connection to the interconnected system.

Figure 11 shows the optimization space for the multiplicative factor of the capital cost of the ocean current power plant as a function of the average speed of ocean currents, for an ocean wave power plant also with a capital cost of US\$ $1,110,000,000$ but for purchased electricity of the grid at US\$ 0.095 per $\mathrm{kWh}$. It is a result with the capital cost of the ocean current power plant equal to the previous figure, Figure 10, but with a lower cost of electricity obtained from the grid. This lower cost of electric energy removed the ocean wave power plants from this optimization space, leaving the connection to the energy system practically as a universal solution, relegating a small area at the bottom right to hybrid solutions with ocean current power plants.

Figure 12 shows the optimization space for the capital cost of the ocean current power plant as a function of the capital cost of the ocean wave power plant, for an average speed of ocean currents of $1 \mathrm{~m} / \mathrm{s}$ and for electrical energy acquired from the system at $\$ 0.095$ per $\mathrm{kWh}$. This figure clearly shows the upper limit of feasibility for ocean wave power plants, which is US\$ 825,000,000. Costs below this amount allow for hybrid solutions with ocean wave power plants and 


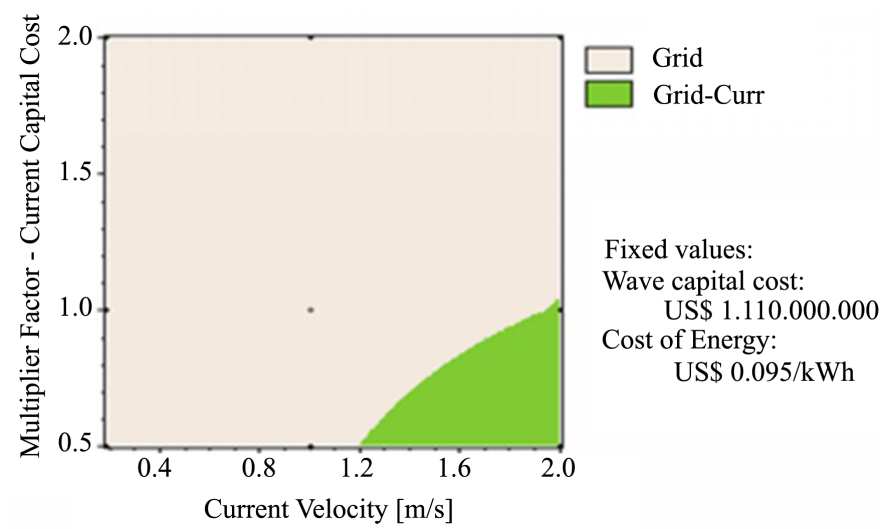

Figure 11. Optimization space for the multiplicative factor of the capital cost of the ocean current power plant (in US\$ millions) as a function of the average speed of ocean currents (in $\mathrm{m} / \mathrm{s}$ ), with the capital cost of the ocean wave power plant equal to US\$1,110,000,000 and electricity purchased from the energy system at US\$ 0.095 per $\mathrm{kWh}$.

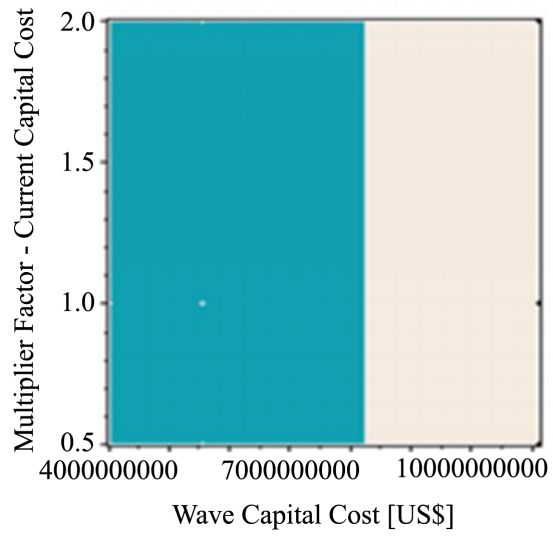

Grid

Grid-Wave

Fixed values:

Average current velocity: $1 \mathrm{~m} / \mathrm{s}$

Cost of Energy:

US\$ 0.095/kWh

Figure 12. Optimization space for the multiplicative factor of the capital cost of the ocean current power plant (in US\$ millions) as a function of the capital cost of the ocean wave power plant (in US\$), with an average current speed of $1 \mathrm{~m} / \mathrm{s}$ and electricity purchased from energy system at US\$ 0.095 per kWh.

connection to the grid, while higher costs include only the connection to the grid. The combination of the average speed of ocean currents and the cost of energy acquired from the energy system, in this case, led to solutions without ocean current power plants.

Figure 13 and Figure 14 show the optimization spaces for the capital cost of the ocean current power plant as a function of the capital cost of the ocean wave power plant, for the average speed of the ocean currents respectively equal to 1 $\mathrm{m} / \mathrm{s}$ and $2 \mathrm{~m} / \mathrm{s}$ for electricity purchased from the grid at US\$ 0.162 per $\mathrm{kWh}$. The increase in the cost of purchased energy enables optimal solutions including ocean wave power plants. The increase in the average speed of ocean currents enables solutions including ocean current power plants with a capital cost with a multiplicative factor less than or equal to 1.5 times the reference value.

The optimal solutions in the next figure always include 45 turbines for converting energy from ocean currents, a result that should be noted. The estimated 


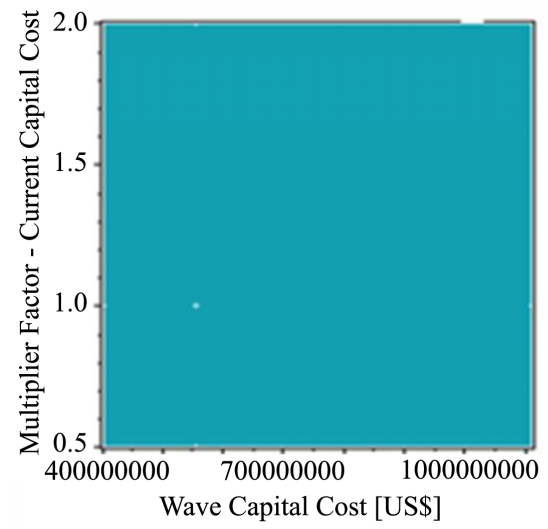

Grid-Wave

Fixed values:

Average current velocity:

$$
1 \mathrm{~m} / \mathrm{s}
$$

Cost of Energy:

US\$ $0.162 / \mathrm{kWh}$

Figure 13. Optimization space for the multiplicative factor of the capital cost of the ocean current power plant (in US\$ millions) as a function of the capital cost of the ocean wave power plant (in US\$), with an average current speed of $1 \mathrm{~m} / \mathrm{s}$ and electricity purchased from energy system at US\$ 0.162 per kWh.

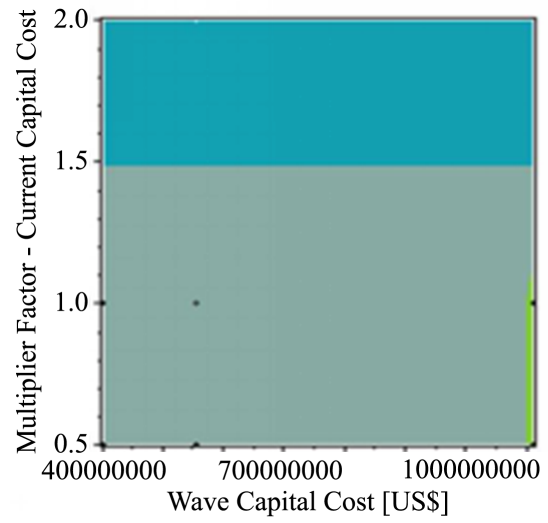

Grid-Wave

Grid-Curr-Wave

Grid-Curr

Fixed values:

Average current velocity:

$2 \mathrm{~m} / \mathrm{s}$

Cost of Energy:

US\$ 0.162/kWh

Figure 14. Optimization space for the multiplicative factor of the capital cost of the ocean current power plant (in US\$ millions) as a function of the capital cost of the ocean wave power plant (in US\$), with an average current speed of $2 \mathrm{~m} / \mathrm{s}$ and electricity purchased from energy system at US\$ 0.162 per kWh.

capital cost of each turbine is US\$12,210,000, resulting in total capital costs equal to US $\$ 549,450,000$. The comparison with the horizontal axis shows that the vast majority of optimal solutions including ocean wave power plants have a higher capital cost for these plants than the capital cost for ocean current power plants.

Figure 15 shows the optimization space for the capital cost of the ocean current power plant as a function of the capital cost for the ocean wave power plant, for the average current speed of $2 \mathrm{~m} / \mathrm{s}$ and for electricity purchased from the grid at US\$ 0.095 per $\mathrm{kWh}$. This optimization space corresponds to the highest average velocity of ocean currents considered in the simulations, with the lowest cost of the electrical energy acquired from the energy system.

The optimization space in this case includes the four combinations of components that have already appeared in the previous figures. A vertical line at US\$ $800,000,000$ marks the division of space considering the solutions that in- 
clude and those that do not include ocean wave power plants. A horizontal line in position corresponding to the reference capital cost of the ocean current power plant separates the optimal solutions including or not including ocean current power plants. The region of this optimization space with the largest area is the one on the top left, corresponding to solutions including ocean wave power plants and connection to the grid. In this case, too, most solutions including power plants have 45 energy conversion devices.

Figure 16 shows the optimization space for the capital cost of the ocean current power plant as a function of the capital cost of the ocean wave power plant, for an average velocity of the ocean currents of $2 \mathrm{~m} / \mathrm{s}$ and for electric energy acquired from the system at US $\$ 0.223$ per $\mathrm{kWh}$. This optimization space corresponds to the results obtained with the highest average velocity of ocean currents and with the highest cost of electrical energy acquired from the grid considered in the simulations.
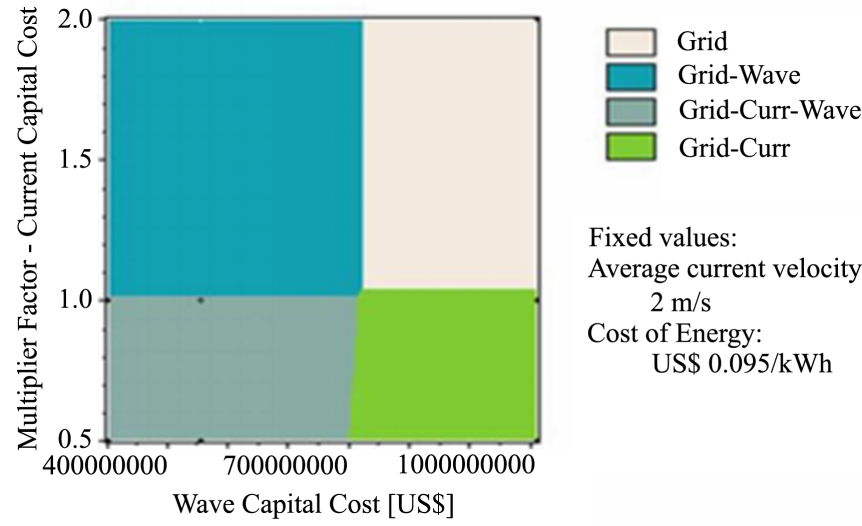

Fixed values: Average current velocity: $2 \mathrm{~m} / \mathrm{s}$

Cost of Energy: US\$ 0.095/kWh

Figure 15. Optimization space for the multiplicative factor of the capital cost of the ocean current power plant (in US\$ millions) as a function of the capital cost of the ocean wave power plant (in US\$), with an average current speed of $2 \mathrm{~m} / \mathrm{s}$ and electricity purchased from energy system at US\$ 0.095 per kWh.

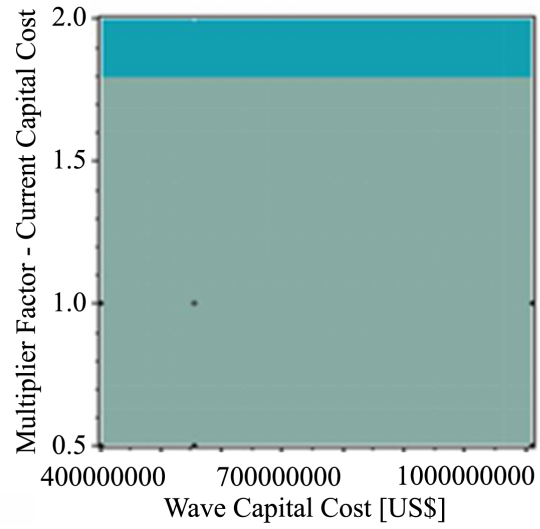

Fixed values:

Average current velocity: $2 \mathrm{~m} / \mathrm{s}$

Cost of Energy:

US\$ $0.223 / \mathrm{kWh}$

Figure 16. Optimization space for the multiplicative factor of the capital cost of the ocean current power plant (in US\$ millions) as a function of the capital cost of the ocean wave power plant (in US\$), with an average current speed of $2 \mathrm{~m} / \mathrm{s}$ and electricity purchased from energy system at US\$ 0.223 per kWh. 
In this case, the higher cost of electricity purchased from the grid makes components with higher capital costs possible. So all optimal solutions include ocean wave power plants and only solutions above the horizontal line located at the position corresponding to the multiplicative factor equal to 1.8 do not include ocean current power plants.

\section{Conclusions}

This article presented a pre-feasibility study of a hybrid system to be operated on the southern coast of Brazil, containing contributions from ocean wave power plants and ocean current power plants. The study was based on simulations performed with the Homer Legacy software and shows the limits for some parameters that establish the technical and economic feasibility for this system.

In general, it can be concluded that the ocean wave power plant, with the characteristics that were considered, shows feasibility in all scenarios except when the ocean wave power plant has a capital cost of US\$ 1.110 million and when the electric power is acquired from the grid at a cost of US\$ 0.095 per $\mathrm{kWh}$.

The ocean current power plant showed limitations in all scenarios analyzed. It shows feasibility for average velocity of ocean currents from approximately 1.1 $\mathrm{m} / \mathrm{s}$ at a cost of US\$ 6,105,000 per energy conversion device, that is, half the estimated capital cost. It also showed feasibility in a scenario with average velocity of ocean currents of $1.6 \mathrm{~m} / \mathrm{s}$, considering the estimated capital cost (US\$12,210,000 per equipment).

As for the scenario for which an average velocity of ocean currents was stipulated at $2.0 \mathrm{~m} / \mathrm{s}$, the estimated capital cost for the ocean current power plant may be double, that is, US\$24,420,000 per equipment, being feasible. All of these factors depend on the price for the purchase of electricity from the national interconnected system.

In the current scenario, with the low average speeds of ocean currents measured in the study region and with the equipment available so far, it can be said that it is not feasible to install devices for converting energy from ocean currents in the regions of this study.

As recommendations for the continuation of this work, the measurement of ocean current velocities at other points of the continental shelf in southern Brazil, looking for locations with higher average speeds, and the design of ocean current energy conversion devices (and their accessories) from average speeds of less intense ocean currents.

\section{Acknowledgements}

This work was developed as part of the activities of the Study Group on Renewable Energies and Sustainability of the Institute of Hydraulic Research, Federal University of Rio Grande do Sul. The authors are grateful for the support received by the institution. The third author is grateful for the support received from CNPq for his work through a research productivity grant (proc.n.312941/ 2017-0) 


\section{Conflicts of Interest}

The authors declare no conflicts of interest regarding the publication of this paper.

\section{References}

[1] Twidell, J. and Weir, T. (2015) Renewable Energy Resources. 3rd Edition, Taylor and Francis, London, 816 p. https://doi.org/10.4324/9781315766416

[2] Bahaj, A.S. (2011) Generating Electricity from the Oceans. Renewable and Sustainable Energy Reviews, 15, 3399-3416. https://doi.org/10.1016/j.rser.2011.04.032

[3] Beluco, A., Souza, P.K., Livi, F.P. and Caux, J. (2015) Energetic Complementarity [of Solar Energy] with Hydropower and the Possibility of Storage in Batteries and Water Reservoirs. In: Sørensen, B., Ed., Solar Energy Storage, Academic Press, Cambridge, 155-188. https://doi.org/10.1016/B978-0-12-409540-3.00007-4

[4] Jurasz, J., Canales, F.A., Kies, A., Guezgouz, M. and Beluco, A. (2020) A Review on the Complementarity between Energy Sources: Concept, Metrics, Application and Future Research Directions. Solar Energy, 195, 703-724.

https://doi.org/10.1016/j.solener.2019.11.087

[5] Odijie, A.C., Wamg, F. and Ye, J. (2017) A Review of Floating Semisubmersible Hull Systems: Column Stabilized Unit. Ocean Engineering, 144, 191-202. https://doi.org/10.1016/j.oceaneng.2017.08.020

[6] Amaechi, C.V., Wang, F., Hou, X. and Ye, J. (2019) Strength of Submarine Hoses in Chinese-Lantern Configuration from Hydrodynamic Loads on CALM Buoy. Ocean Engineering, 171, 429-442. https://doi.org/10.1016/j.oceaneng.2018.11.010

[7] Zhang, H., Xu, D., Xia, S. and Wu, Y. (2017) A New Concept for the Stability Design of Floating Airport with Multiple Modules. Procedia IUTAM, 22, 221-228. https://doi.org/10.1016/j.piutam.2017.08.025

[8] Amaechi, C.V., Gillett, N., Odijie, A.C. Hou, X. and Ye, J. (2019) Composite Risers for Deep Waters Using a Numerical Modelling Approach. Composite Structures, 210, 486-499. https://doi.org/10.1016/j.compstruct.2018.11.057

[9] Thiagarajan, K.P. and Dagher, H.J. (2014) A Review of Floating Platform Concepts for Offshore Wind Energy Generation. Journal of Offshore Mechanics and Arctic Engineering, 136, Article ID: 020903. https://doi.org/10.1115/1.4026607

[10] Doyle, S. and Aggidis, G.A. (2019) Development of Multi-Oscillating Water Columns as Wave Energy Converters. Renewable and Sustainable Energy Reviews, 107, 75-86. https://doi.org/10.1016/j.rser.2019.02.021

[11] Assis, L.E., Beluco, A. and Almeida, L.E.B. (2014) On the Wave Energy Potential along the Southern Coast of Brazil. International Journal of Energy and Environment, 5, 59-66. https://doi.org/10.5935/2076-2909.20140002

[12] Fischer, A. and Almeida, L.E.B. (2016) Converting Energy from Ocean Currents. International Journal of Research in Engineering and Technology, 5, 220-227.

https://lume.ufrgs.br/handle/10183/184300 https://doi.org/10.15623/ijret.2016.0503044

[13] Silva, J.S. and Beluco, A. (2018) Characterization of a Feasibility Space for a New Technology-A Case Study of Wave Energy in Southern Brazil. Current Alternative Energy, 2, 1-11. https://doi.org/10.2174/1570178615666180830102336

[14] Silva, J.S. and Beluco, A. (2020) A "Feasibility Space" as a Goal to Be Achieved in the Development of New Technologies for Converting Renewable Energies. $\mathrm{Me}$ - 
thodsX, 7, Article ID: 100960. https://doi.org/10.1016/j.mex.2020.100960

[15] HomerEnergy. Software HOMER, versão 2.68 beta. The Micropower Optimization Model. http://www.homerenergy.com

[16] IBGE. Instituto Brasileiro de Geografia e Estatística (2020) Censo Demográfico de 2010. Total da população do Rio Grande do Sul. http://www.ibge.gov.br/home

[17] Assis, L.E., Beluco, A. and Almeida, L.E.B. (2013) Avaliação e aproveitamento da energia de ondas oceânicas no litoral do Rio Grande do Sul. Revista Brasileira de Recursos Hídricos, 18, 21-29. https://doi.org/10.21168/rbrh.v18n3.p21-29

[18] Fischer, A., Beluco, A. and Almeida, L.E.B. (2013) Preliminary Determination of the Energy Potential of Ocean Currents along the Southern Coast of Brazil. International Journal of Energy and Environment, 4, 879-894. https://doi.org/10.5935/2076-2909.20130001

[19] Fischer, A., Beluco, A. and Almeida, L.E.B. (2013) Energetic Potential and Variability of Ocean Currents on the Southern Coast of Brazil. IEEE Latin America Transactions, 13, 1369-1375. https://doi.org/10.1109/TLA.2015.7111991

[20] Lambert, T.W., Gilman, P. and Lilienthal, P.D. (2005) Micropower System Modeling with HOMER. In: Farret, F.A. and Simões, M.G., Eds., Integration of Alternative Sources of Energy, John Wiley \& Sons, West Sussex, 379-418. https://doi.org/10.1002/0471755621.ch15

[21] Lilienthal, P.D., Lambert, T.W. and Gilman, P. (2004) Computer Modeling of Renewable Power Systems. In: Cleveland, C.J., Ed., Encyclopedia of Energy, Elsevier, Amsterdam, Vol. 1, 633-647, NREL Report CH-710-36771.

https://doi.org/10.1016/B0-12-176480-X/00522-2

[22] Connolly, D., Lund, H., Mathiesen, B.V. and Leahy, M. (2010) A Review of Computer Tools for Analyzing the Integration of Renewable Energy into Various Energy Systems. Applied Energy, 87, 1059-1082. https://doi.org/10.1016/j.apenergy.2009.09.026

[23] Beluco, A., During Filho, F.A., Silva, L.M.R., Silva, J.S., Teixeira, L.E., Vasco, G., Canales, F.A., Rossini, E.G., Souza, J., Daronco, G.C. and Risso, A. (2020) Dataset after Seven Years Simulating Hybrid Energy Systems with Homer Legacy. Data Science Journal, 19, 14. https://doi.org/10.5334/dsj-2020-014

[24] Beluco, A., During Filho, F.A., Silva, L.M.R., Silva, J.S., Teixeira, L.E., Vasco, G., Canales, F.A., Rossini, E.G., Souza, J., Daronco, G.C. and Risso, A. (2020) Seven Years Simulating Hybrid Energy Systems with Homer Legacy. Mendeley Data, Vol. 2.

[25] Canales, F.A. and Beluco, A. (2014) Modeling Pumped Hydro Storage with the Micropower Optimization Model (HOMER). Journal of Renewable and Sustainable Energy, 6, Article ID: 043131. https://doi.org/10.1063/1.4893077

[26] Canales, F.A., Beluco, A. and Mendes, C.A.B. (2017) Modelling a Hydropower Plant with Reservoir with the Micropower Optimization Model (HOMER). International Journal of Sustainable Energy, 36, 654-667. https://doi.org/10.1080/14786451.2015.1080706

[27] Fischer, A., Silva, J.S., Beluco, A. and Almeida, L.E.B. (2015) Simulating Ocean and Tidal Current Power Plants with Homer. Computational Water, Energy and Environmental Engineering, 4, 38-55. https://doi.org/10.4236/cweee.2015.43005

[28] Silva, J.S., Beluco, A. and Almeida, L.E.B. (2013) Simulating an Ocean Wave Power Plant with Homer. International Journal of Energy and Environment, 5, 619-630. https://doi.org/10.5935/2076-2909.20140001 
[29] Fischer, A., Silva, J.S. and Beluco, A. (2020) A Hybrid System with Ocean Wave and Ocean Current Power Plants in Southern Brazil. Mendeley Data, Vol. 1.

[30] Assis, L.E. (2010) Evaluation and Use of Ocean Wave Energy on the Coast of Rio Grande do Sul [In Portuguese]. Master Dissertation in Water Resources, Universidade Federal do Rio Grande do Sul, 82 p. http://hdl.handle.net/10183/32464 